\title{
COMMISSION 46: TEACHING OF ASTRONOMY (ENSEIGNEMENT DE L'ASTRONOMIE)
}

\author{
Report of Meetings, 19 and 21 August 1970
}

President: E. A. Müller.

SECRETARY: T. L. Swihart.

\section{First Session}

\section{Membership}

The President explained the policy of the Commission concerning membership. Each country adhering to the IAU should have a representative in Commission 46 in charge of making the liaison between the activities of the Commission and the astronomy teachers in the various institutions and all what concerns the teaching of astronomy in his (or her) own country. Every member representative should be designated or approved by his (or her) National Committee of Astronomy. Two countries previously without representation were added to the Commission: Austria, represented by H.F. Haupt, and Brazil by S. Ferraz-Mello. By personal contacts during the Brighton meetings the President added the following countries to the Commission: Indonesia, represented by B. Hidayat; Iran by $A$. Therian, Finland by K. A. Hämeen-Anttila, and Yugoslavia by F. Dominko.

The Presidnet then proposed that the Organizing Committe of the Commission should consist of the President, the Past-President, the Vice-President, and of those members in charge of continuing or developing one of the projects of the Commission, and such others as considered necessary by the President.

\section{Commission Report}

No special remark was made concerning the report prepared for the IAU Transactions XIVA.

\section{National Reports}

The President remarked that a mimeographed copy of the reports on national activities in astronomy education could be consulted in the book exhibition at the University of Sussex on the occasion of the IAU meeting.

G. O. Abell gave a summary of activities of the Committee for Education in Astronomy (CEA) in the U.S. The CEA is an official organ of the American Astronomical Society and its purposes are similar to those of Commission 46 except on a national rather than international level. $R$. E. Berendzen announced that an International Conference on Astronomy Education and on the History of Modern Astronomy will be held from August 30 to September 1, 1971, in New York City. Participation from as many countries as possible is desired. Interested persons unable to attend are encouraged to send relevant material or information to Berendzen (Dept. of Astronomy, Boston University, Boston, Mass. 02215, U.S.A.)

\section{The IAU/UNESCO International Schools for Young Astronomers}

J. Kleczek reported on the previous schools held in England (1967), Italy (1968), and India (1969). The 1970 ISYA is to be held in Argentina during October and November. The purpose of the schools is to give a concentrated expert instruction and training in special topics of modern astronomy for a small number of selected young astronomers or physicists, with or without Ph.D., who otherwise would not have such opportunities available to them. If funds are available future ISYA will be planned, one every year. $J$. Kleczek had agreed to continue serving as Secretary of 
the ISYA for another three-years term. It was felt that an Assistant Secretary of the ISYA should be designated to help Kleczek in his important task. As a result of numerous privateconsultations before and during the Brighton meetings the President invited I. Atanasijević to serve as Assistant Secretary of the ISYA. He was introduced to the Commission in the beginning of the fourth session.

\section{The Visiting Professors Project}

Speaking for M. Minnaert, who most regrettably was absent due to illness, $E$. A. Müller reported on this project. The aim is to provide contacts between places remote from main centres of astronomical research which could benefit by the visit of an astronomer teaching a course of particular interest to them and possibly helping them develop a research and/or teaching programme on the one hand, and, on the other, astronomers who would be willing and able to make such visits. India, Indonesia and Uruguay had previously indicated a desire for such visits, and Brazil also responded at the present meeting. One of the problems is to find the capable astronomers who can devote some of their time to go and teach, stimulate, and encourage astronomical research at one of the interested institutions. Another problem is the funding of such visits. In some cases living expenses for the duration of the visit can be provided by the host institution, but travel expenses are quite another matter. It was suggested that such visits could perhaps be combined with other sanctioned travel of the interested astronomers. For example, a visit to Brazil and Uruguay could be accomplished by an astronomer whose observing schedule takes him to one of the observatories in Chile. It was also pointed out that the solar eclipse in Africa in 1973 could provide for such visits to that continent. The President proposed that $M$. Minnaert should continue to be in charge of this project.

After the session R. Steinitz informed the Commission Secretary that he would be willing to devote some time as Visiting Professor in one or the other of the South American countries.

\section{The ICSU Committee on Science Teaching}

As representative of the ICSU Committee on Science Teaching (CST) E. A. Müller mentioned the formation, the purpose, the activities and the plans of the CST which she had described briefly in the Assembly Times No. 2 of 19th August 1970. The main objectives of the CST are (a) to further on an international scale progress in the teaching of science at all levels, (b) to co-operate with other organizations concerned with any aspect of the teaching of science, (c) to facilitate co-operation among the teaching committees of the individual scientific unions. The Committee consists of the Chairman and six members appointed by ICSU and of one representative of each Scientific Union, member of ICSU, interested in the teaching of science. Some observers of the UNESCO Division of Science Teaching are invited to attend the Committee's meetings and to collaborate with the Committee in the programmes which are of mutual interest. A major conference on science education is envisaged for 1972 or 1973 which will be concerned with the various aspects of the training and re-training of science teachers for the teaching of integrated science. Before this major conference one or two symposia on specific topics are planned for 1971 and 1972. E. A. Müller agreed to continue to represent the IAU on the ICSU Committee of Science Teaching.

\section{Integrated Sciences}

E. $A$. Müller pointed out that in many countries astronomy education in primary and secondary schools is quite inadequate. Since only few schools can offer a separate course in astronomy, astronomy should be integrated into courses, in particular physics. She suggested that perhaps Commission 46 should start a project of preparing leaflets or teacher's guides on selected topics of modern astronomy which would explain the topics and show how they relate to topics in physics, for example. Some material already in existence, which may at least partially achieve these aims, were mentioned. E. Schatzman stated that he thought the best approach is to work directly with the physicists. If we can educate them so that they understand astronomy adequately, physics courses will auto- 
matically give a more balanced approach in which astronomy is given proper coverage. The decision of the Commission on the suggested project was postponed to a later session.

\section{The International Exchange and/or Unilateral Gifts of Teaching Material in Astronomy}

D. McNally brought up the problem of the large expenses of many essential educational materials for developing countries and the situation of countries with currency exchange problems. One possible answer is that those institutions, organizations or individuals which can afford to do so, make materials available as gifts. $B$. Bok mentioned how he goes about sending scientific literature directly to developing institutions. He also suggested that the Commission contact the UNESCO representatives to see what they would suggest. It was agreed that $D$. McNally would be in charge of this project. The President mentioned that UNESCO issues coupons for developing countries which can be exchanged for books published in any country. The conditions are different for each country. All countries eligible for UNESCO assistance have a UNESCO representative who can be contacted directly or through the local Ministry of Education or its equivalent.

\section{The Contratype Project (CP)}

E. K. Kharadze described a project proposed by himself, E. V. Kononovich and E. K. Straut which consists of providing a clearing house where slides, pictures, etc., of reasonable current interest could be made available for reproduction to anyone interested. This is for educational rather than research purposes. All interested observatories would provide materials (suitably standarized if necessary) to the central headquarters of the CP. Anyone interested could have the desired materials sent to them for reproduction, and the originals would then be returned to CP. As D. Wentzel had been involved in a similar type project it was suggested that he meet Kharadze to discuss details. The President proposed that E. K. Kharadze, E. V. Kononovich and D. Wentzel should be in charge of the CP. Miss M. Gerbaldi agreed to act as secretary of this group.

\section{Astronomy Educational Material}

It was announced that in order to be useful the list of AEM should be updated every three years for each General Assembly. T. L. Swihart would collect the English materials and V. Kourganoff would be in charge of compiling the materials of the non-English countries by asking the Commission members of all countries for collaboration.

\section{Second Session}

This session was devoted to the discussion of the list of Astronomy Educational Material which had been prepared by Commission 46 for this General Assembly. E. A. Müller explained that the AEM list was prepared for the benefit of teachers and students of all levels and, in particular, it was aimed to serve as guideline to those institutions and persons all over the world who were trying to build up an astronomical library and/or get some astronomy going. She pointed out that a strict and careful selection had to be made as to the usefulness of each item for the teachers and the students. Of the language that she could judge she felt that the items in French, German and Italian had been very well selected, but that the books in English had not been carefully selected. It was decided that as far as the items in English go, some weeding out was to be done to make the list more useful and the US members of the Commission were invited to do this. $P$. V. Sudbury proposed that the AEM should include a list of planetarium manufacturers, the planetaria being a very useful astronomy teaching aid for schools and colleges. The Commission decided that such a list should be included in the AEM, and Sudbury agreed to compile the list.

The main problem is the publication, the price and the distribution of the AEM compilation. In order to be really useful, it should have a large, world-wide distribution. The question is how to go 
about this. Some members of the audience felt that the present form of the AEM was satisfactory, others indicated that the publication of the AEM in its present form would be too expensive. $B$. Bok suggested that the Commission should contact UNESCO who might be the agency for a worldwide distribution of the AEM. The President agreed to do so.

It was decided that for the time being the AEM would be kept in its present form. Each Commission member has a copy of the AEM and has the task to publicize the existence of this compilation to astronomy or science institutions, to teachers associations and others in his (or her) own country. Orders for copies could be sent to the President who could provide mimeographed copies for a modest price covering the paper and mailing costs.

\section{Third Session}

At the beginning of this session $D$. Wentzel reported on the meeting he had with $E$. K. Kharadze and $M$. Gerbaldi concerning the Contratype Project. They decided on the following: The major observatories would be contacted and asked to supply contact prints of current interest to the $\mathrm{CP}$ file. These will then be sent to any institution on demand for reproduction; the originals will then immediately be returned to the CP. Costs will thus be limited essentailly to postage. The file will constantly be updated and information on what is available will be periodically circulated. It was again stressed that this is for educational not research purposes. The present secretary for the CP is Miss M. Gerbaldi, Institut d'Astrophysique, Paris, France. Here the file will be established, at least for the time being. Notice will be given when the CP is ready to receive requests. It was emphasized that southern hemisphere material should be included. D. McNally also stressed that care should be taken that no copyright problems might arise, i.e. to ascertain that the user is free to reproduce the material in any way he wishes.

The session was then devoted to discussions concerning astronomy education at the primary and secondary school level. Everyone realised the importance of giving some basic knowledge of modern astronomy to the general public, the school children and, in particular, to the science teachers. The discussions mainly dealt with the basic questions of how astronomy should be introduced in schools and how the science teachers should be guided and instructed in modern astronomy. Since most schools do not offer a separate course in astronomy, the importance of integrating astronomy in science courses, mainly physics, was stressed. $D$. McNally pointed out that the students at this age group, growing up in the space age, are much more aware of the recent advances than their science teachers and, therefore, the teachers must currently be brought up-to-date. $F$. Egger said that astronomy should not be introduced simply as an application of mathematics and physics but students actually need some practical experience in astronomy (simple observational experiments, school telescopes, planetaria). He thinks that the curriculae introducing astronomy should be prepared by the teachers themselves with the aid of professional astronomers, and not vice versa. $W$. Buscombe gave an example of a text written by physicists who knew little astronomy thus giving a misleading view of the subject. However, the project was so expensive that the schools concerned are stuck with the text for years to come. $R$. $A$. Coutrez suggested that astronomy should be integrated into the methodology of science at high schools. The President mentioned a paper prepared by $E . V$. Kononovich and E. K. Straut on the Astronomy education in Soviet schools. In the U.S.S.R. the methodology of school astronomy has been worked out as described in the paper. Due to absence from Brighton of both authors, their paper was not further discussed. A few recent teachers' guides and projects of integrated sciences were then mentioned. P.V. Sudbury called attention to the book Learning about space (published by H. M. Stationary Office, London) as a teacher's guide for children aged 7-13. E. A. Beet mentioned the Nuffield Physics Project in England for ages 11-16, and he said that the teachers hesitate to introduce the project because they are not trained in this system. $R$. Berendzen described a programme called Search for life in the universe designed for ages 13-15. It unifies many sciences and is inquiry oriented. Text and teachers' guides are available as are consultants (in the Boston area only, at present). He also mentioned that pre-college level books, slides, filmloops etc. are available from NASA Bibliography, Washington, D.C. O. Gingerich 
described the Harvard Project Physics (published by Holt, Rinehart and Winston), a secondary school physics course which in its second unit introduces in a historical sequence (from Greek astronomy, through Copernicus, Kepler and Newton) selected astronomical materials. Good radio and television programmes in Astronomy can be very useful. $R$. Steinitz, for example, reported that the Astronomy programmes on the Israel radio were very successful. The teachers were forced to keep up on the subject because the students had followed the radio course and then came up with many further questions to their teachers. C. Titulaer described a course in Astronomy prepared for the Netherlands television starting in early 1971. It consists of a series of 12 lessons each of 25 minutes duration. Information is available from TELEAC, Postbus 2414, Utrecht, The Netherlands.

Coming back to the question from the first meeting, the President asked whether the Commission should actively prepare materials to aid astronomy education in schools. G. O. Abell felt that this is properly the job of individuals rather than of the Commission itself. The concensus of the audience was that the Commission should not prepare aids for astronomy teaching but that it should encourage persons who have abilities in preparing such materials to do so. The task of the Commission is to disseminate the available information on astronomy teaching aids.

\section{Fourth Session}

The President opened the session by presenting to the Commission a set of 10 Rules of Operation governing the Commission. After a brief discussion and some change in wording the proposed rules were accepted by a vote of the Commission members present. J.-C. Pecker asked that the rules should be made available to the various National Committees. The Commission rules then were handed over to the IAU General Secretary for further handling.

$R$. A. Coutrez then read a recommendation by the Belgium National Committee on astronomy. After some discussion on the wording the following recommendation was put to a vote and accepted by the Commission members present: "Commission 46 recommends that a sufficiently extended course on basic modern astronomy, which might be optional, should be maintained or incorporated within the programmes of the first years of university teaching for the undergraduate students of colleges of arts and science as well as colleges of engineering."

The French version of the recommendation reads as follows:

"La Commission 46 recommande qu'un cours de base suffisamment étendu sur les éléments d'astronomie moderne, cours eventuellement à option, soit maintenu ou incorporé dans les programmes des premières années de l'enseignement universitaire donné aux étudiants des facultés des sciences exactes et appliquées et des écoles d'ingénieurs."

The Commission's recommendation was passed on to the IAU General Secretary for further handling.

The rest of the session was devoted to discussions on the education in astronomy at the general university level and on the education of astronomers. Concerning astronomy for non-sciences student $R$. Berendzen and $O$. Gingerich described projects which emphasize the historical development of astronomy. It was pointed out, however, that the historical approach requires very experienced teachers. $D$. Wentzel remarked that often astronomy is the only science course a student takes at the University. Therefore, in such a course things should be stressed that are important for science in general and not only for astronomy. How this is done at the University of Maryland is described by Wentzel in an article to appear in the American Journal of Physics in early 1971. $R$. Leclaire mentioned the pioneering course SPACE AND MAN introduced by the Department of Education in Ontario giving guidelines to teachers and students for studies centred on space. It is an interdisciplinary course which extends through the humanities and the sciences, thus giving the student a general education rather than a training in any one discipline.

A discussion followed dealing with the question of when to introduce astronomy into the curriculum of science students. Various opinions were presented and no final conclusion was reached. Whereas $R$. Steinitz thinks that astronomy might be more effectively taught in later rather than earlier years when students have better backgrounds, $D$. McNally said that astronomy should be 
taught soon to physics and other science students so as not to postpone their exposure. As much as possible astronomy should be integrated with other science subjects - the barriers between them should be cut down. This is important in view of the fact that some of these science students will be future high school teachers. E. Schatzman stated that often physics students resist taking separate courses in astronomy and, therefore, they should get their astronomy education directly in the physics courses. To this end more astronomy oriented persons must get into physics chairs. J.-C. Pecker stressed that in training scientists one should not neglect to teach the students how to use a library, look up references, etc. For the practical training $D$. Wentzel announced the availability at low cost of selected prints from the Palomar Sky Survey and certain Moon photographs released by NASA. The six Palomar prints for use in laboratory exercises may be ordered at the Caltech Bookstore, CALTECH, Pasadena, California 91109, U.S.A. The Lunar Photographs for Lecture and Laboratory may be ordered at Bara Photographic Inc., 4805 Frolich Lane, Hyattsville, Maryland 20781, U.S.A.

Concerning the education of astronomers $U$. Steinlin stressed the importance of laboratory exercises and practical training of the students. He described inexpensive equipment constructed at the Observatory in Basel with students' needs specifically in mind. Details could be made available on request. Many members of the audience expressed their hope that the detailed information and description would soon be published. On the graduate level E. Schatzman strongly recommended that students take part in research projects as early as possible. Taking formal courses and examinations is not the only or the best way of finding the best future research workers. E. A. Müller commented on the need and the usefulness of concentrated schools of one to two weeks duration on some selected subject for advanced astronomy students of smaller institutions.

Due to lack of time the training of space astronomers was not discussed. Th. Page had sent a paper on this subject, but he was not present at Brighton to present and discuss it. 